\title{
Teoria do Custo de transação e escolha de modos de entrada \\ no mercado Internacional
}

\section{Matheus Alexsandro Teófilo Alves, Vinicius Farias Moreira, Yákara Vasconcelos Pereira}

\author{
Universidade Federal de Campina Grande \\ Universidade Federal de Campina Grande \\ Departamento de Ciências Administrativas \\ Universidade Federal de Pernambuco
}

Esta pesquisa possui o objetivo de analisar, a partir da Teoria de Custo de Transação (TCT), a escolha do modo de entrada em mercado internacional, do maior trader comercial de metais finos do nordeste brasileiro, sediado na cidade de Maceió-AL. Esta investigação se classifica como um estudo de caso único, de caráter qualitativo. A coleta de dados foi realizada por meio de entrevistas semiestruturadas, observaçáo participante e análise documental. Os resultados indicam que os cinco pressupostos, gerados com base na TCT, têm relativo sucesso ao explicar a influência dos fatores propostos na escolha do modo de entrada da empresa analisada. Os pressupostos mais relevantes na escolha foram: o que analisa o custo de transação, as demandas legais para internacionalizaçáo e o que pondera sobre a especificidade do ativo. Os demais pressupostos náo apresentaram influência na escolha do modo de entrada.

Palavras-chave: modo de entrada, Teoria do custo de transaçáo, Internacionalização, Negócios internacionais

\section{Transaction Cost Theory and Choice of Ways to Enter the International Market}

This research aims to analyze, based on the Transaction Cost Theory (TCT), the choice of the way to enter the international market, of the largest commercial trader of fine metals in the Brazilian Northeast, based in the city of MaceióAL. This investigation is classified as a single case study, with a qualitative character. Data collection was carried out through semi-structured interviews, participant observation and document analysis. The results indicate that the five assumptions, generated based on the TCT, are relatively successful in explaining the influence of the factors proposed in the choice of the entry mode of the analyzed company. The most relevant assumptions in the choice were the one that analyzes the transaction cost, the legal demands for internationalization and the one that considers the specificity of the asset. The other assumptions had no influence on the choice in the case studied.

Keywords: entry mode, transaction cost theory, internationalization, international business

\section{Teoría del costo de transacción y elección de formas de ingresar al mercado internacional}

Esta investigación tiene como objetivo analizar, a partir de la teoría del costo de transacción (TCT), la elección de la forma de ingresar al mercado internacional del mayor comercializador de metales finos del nordeste brasileńo, con sede en la ciudad de Maceió-AL. Esta investigación se plantea como un estudio de caso único, de carácter cualitativo. La recolección de datos se realizó mediante entrevistas semiestructuradas, observación participante y análisis documental. Los resultados indican que los cinco supuestos, generados sobre la base de la TCT, son relativamente exitosos en 
explicar la influencia de los factores propuestos en la elección del modo de ingreso de la empresa analizada. Los supuestos más relevantes en la elección fueron el que analiza el costo de transacción, las exigencias legales de internacionalización y el que considera la especificidad del activo. Los demás supuestos no influyeron en la elección en el caso estudiado.

Palabras clave: modo de entrada, teoría del costo de transacción, internacionalización, negocios internacionales

\section{Introdução}

Apesar de sempre presentes na história da humanidade, as transações entre diferentes países nunca antes foram tão expressivas. O século XX foi marcado por revoluçóes que abalaram as estruturas políticas e econômicas mundiais. No aspecto econômico, os fortes ventos proclamando o liberalismo econômico e o livre comércio impulsionaram mais e mais países a eliminar barreiras comerciais e abrir suas fronteiras aos investimentos estrangeiros, fortalecendo ações da Organização Mundial do Comércio. A adesão à internacionalização foi tão expressiva que Bennet., Bennett, Burstein, e Holsapple (2008) chegou a constatar que entre os anos de 1984 e 1998 o volume total de investimento empresarial no exterior aumentou dez vezes.

A internacionalização de empresas é um tópico de estudo relevante dentro do ambiente das decisóes estratégicas organizacionais e vem contribuindo no campo teórico e empresarial (Andresen \& Bergdolt, 2017; Hitt, Ireland \& Hoskisson, 2018). Os estudos e teorias de internacionalização se intensificaram, tornando-se uma das áreas mais estudada na área de administração (Canabal \& White, 2008; Prange \& Pinho, 2017; Werner, 2002). Ao observar que a internacionalização trazia novas soluçóes e desafios para as empresas, Agarwal e Ramaswami (1992) argumentam que a decisão de maior impacto sobre o processo de internacionalização das empresas estava concentrada em uma das primeiras decisóes, a qual se configura na escolha do modo de entrada a ser utilizada para ingres- sar no mercado internacional. Para compreender quais fatores deveriam ser priorizados na escolha do modo de entrada, pesquisadores como Erramilli e Rao (1993), Brouthers e Brouthers (2001), e Brouthers (2013) utilizaram premissas e abordagens teóricas já canonizadas no meio acadêmico para justificar a escolha do modo de entrada em detrimento das demais opçóes.

O presente artigo seleciona a Teoria do Custo de Transação (TCT) de Williamson (1979) para partir como ponto de apoio principal, tendo em vista que essa teoria é considerada a principal referência de suporte para analisar os fatores de influência da escolha, ao considerar a maior quantidade de fatores das teorias propostas até então e apresentando resultados relevantes para as empresas. Roberts e Greenwood (1997), Oliver (1997) e Brouthers (2013) relatam que a decisão de modo de entrada pode ser explicada pelos pressupostos gerados da TCT.

Além disso, Chiles e Mcmackin, (1996) e Roberts e Greenwood (1997) afirmam que a adoção de outras teorias para embasar a decisão do modo de entrada, muitas vezes não atende satisfatoriamente às demandas da empresa que acabam lenta e gradativamente conduzidas à falência. Diante da relevância do tema e da sua contemporaneidade para a ciência (Schellenberg, Harker \& Jafari, 2018), alcança-se o seguinte problema de pesquisa: como, a partir da Teoria de Custo de Transação, ocorre a escolha do modo de entrada em mercado internacional, do maior trader comercial de metais finos do Nordeste, sediado na cidade de Maceió-AL? 
Desse modo o presente artigo tem como objetivo analisar, a partir da Teoria de Custo de Transação, a escolha do modo de entrada em mercado internacional, do maior trader comercial de metais finos do Nordeste, sediado na cidade de Maceió-AL. A empresa cujo processo de escolha do modo de entrada foi analisado faz parte do setor de sucata, comercializa metais finos também conhecidos como metais não ferrosos, como alumínio e ligas de inox, tanto para o mercado nacional quanto para mercados externos. Estudos sobre empresas do setor da sucata são necessários no Brasil, uma vez que o país exportou mais de 10 mil toneladas de alumínio na forma de sucata para o exterior em 2018 (Ministério da Indústria, Comércio Exterior e Serviços, 2019) e a reutilização de recursos naturais é um assunto de expressiva magnitude nos tempos atuais. Além disso, ao pesquisar no portal de Periódicos da CAPES, o principal portal de artigos do país, raras são as pesquisas realizadas sobre esse segmento econômico na área de estratégia em administração, mostrando-se relevante a realização desta pesquisa.

\section{Internacionalizaçáo e os modos de entrada no mercado internacional}

Após o estabelecimento da Organização Mundial do Comércio, as barreiras previamente desenvolvidas para tentar frenar o livre comércio foram gradativamente eliminadas. Isso permitiu que as economias mundiais tivessem maior contado entre si e que suas interaçóes se multiplicassem, o que transformou a realidade mercadológica, estabelecendo-se um mercado global (Maia, 2013).

A internacionalização empresarial pode então ser compreendida como o desempenho de atividades de comércio e investimento realizados por empresas para além das fronteiras de seu país sede. Essas empresas organizam, abastecem, fabricam, comercializam e con- duzem outras atividades de valor agregado em escala internacional, buscando consumidores estrangeiros e mantendo relacionamentos colaborativos com parceiros overseas (Cavusgil, Knight \& Riesenberger, 2009).

Entende-se que a internacionalização é utilizada como uma estratégia empresarial, ou seja, um meio para a obtenção de melhores resultados organizacionais (Oviatt \& McDougal, 1994; Zahra \& George, 2002). Quanto aos motivos que levam uma empresa à internacionalização, podem ser destacados a inatividade do mercado interno (Root, 1994), prospecção de vendas imediatas (Root, 1994), os incentivos governamentais do país hospedeiro (Porter, 1999; Root, 1994) o networking (Johanson \& Vahlne, 2009; Porter, 1999), a transação de recursos (Porter, 1999), acesso à tecnologia (Dhanaraj \& Beamish, 2003), aspectos de competição (Porter, 1999), as estruturas da empresa que almeja o mercado internacional (Dhanaraj \& Beamish, 2003) e a identificação de oportunidades em mercados exteriores (Johanson \& Vahlne, 1977). De modo geral pode-se afirmar que as empresas utilizam a internacionalização como uma estratégia para buscar oportunidades no mercado internacional e criar valor (Mtigwe, 2006; Zahra \& George, 2002).

Observando a importância da internacionalização para o aumento da competitividade e crescimento geral das organizações, Agarwal e Ramaswami (1992) argumentam que uma das decisóes estratégicas de maior impacto no processo de internacionalização de uma empresa é a decisão do melhor modo de ingressar no mercado estrangeiro. $\mathrm{O}$ modo de entrada no mercado estrangeiro é um arranjo institucional e organizacional que objetiva a viabilizar a entrada de produtos, tecnologia, habilidades humanas, gerenciamento e mais notoriamente produtos e serviços, assim como outros recursos organizacionais no mercado estrangeiro (Hymer, 1960; Root, 1994). 
Não existem divergências teóricas acentuadas sobre quais são efetivamente os modos de entrada de atendimento ao mercado exterior (Schellenberg et al., 2018), entende-se que podem abranger desde a exportação, direta ou indireta, de bens ou serviços até a internacionalização parcial ou completa da produção da firma, na forma de investimentos diretos (Cassol, Novakowski, Dalbosco \& Tonial, 2016). Dentre os principais modos de entrada destacam-se: exportação; licenciamento, franquias, associaçóes e alianças estratégicas, joint ventures e subsidiárias (Iglesias \& Veiga, 2002; Peng, 2012).

Existe um conjunto de fatores influentes na escolha do modo de entrada, que deveria ter mais importância no momento da tomada de decisão e que nem sempre são os mesmos para todas organizaçóes que almejam a internacionalização (Steinbruch, Soares, Nunes, Perin, \& Sampaio, 2016). Os fatores são separados em grupos de acordo com o escopo de atuação, que compreendem fatores ambientais do mercado-alvo; do ambiente industrial; fatores internos da empresa e fatores observados nos produtos (Osland, Taylor \& Zou, 2001; Sharma \& Erramili, 2004).

Buscando justificativas cientificamente plausíveis para compreender os motivos pelos quais as empresas escolhem determinado modo de entrada, pesquisadores consideram teorias já estabelecidas para definir quais fatores devem ser mais influentes no processo de escolha, considerando que a análise de diferentes aspectos pode levar a conclusóes divergentes (Gama, Lana, Calixto, \& Bandeira-de-Mello, 2016; Meyer, 2015). Dentre as teorias selecionadas destacam-se: a teoria institucional, teoria das opçóes reais, teoria do custo de transaçáo (TCT), teoria do poder de barganha, o Modelo de Uppsala de internacionalização e a teoria do custo de comunicação. Para efeito deste artigo foi analisada a escolha do modo de entrada sob a luz dos fatores sugeridos pela teoria do custo de transação (Williamson, 1979; 1994), tendo em vista que esses caminhos proporcionam às firmas a estrutura mais eficiente para atuar no exterior (Shrader, 2001; Shelanski \& Klein, 1995), visto que na TCT a existência de qualquer composição organizacional tem sua eficiência de custos comparada as demais opçóes.

\subsection{A teoria do custo de transaçáo e a escolha do modo de entrada}

O termo custo de transação foi apresentado pela primeira vez por Coase, em 1937, na publicaçâo intitulada "A natureza da firma", na qual define o custo de uso do mecanismo de preço. O autor utilizou esse termo para criar um framework que objetivava prever quando certas atividades econômicas seriam realizadas pelas próprias firmas e quando seriam obtidas pelas firmas por outsourcing (Coase, 1937).

Pode-se dizer que a maior problemática que a teoria busca sanar é o motivo das transaçóes serem organizadas do modo que são na sociedade moderna e, mais especificamente, porque algumas transaçóes econômicas ocorrem dentro das empresas e outras ocorrem entre a empresa e o mercado. A conclusão alcançada no estudo é que as atividades são realizadas internamente quando existe alguma falha no mercado em atender as demandas realizadas pelas empresas com eficácia e eficiência (Williamson, 1994).

Mantendo essa vertente, Williamson (1994) também argumenta que a firma, em muitos casos, consegue ser mais eficiente no desempenho de algumas atividades que o mercado, porque geralmente têm mais facilidade em otimizar o custo de transação e consequentemente o custo total do produto. Assim, a TCT considera que a organização está sempre em busca do upgrade em eficiência resultante da redução do custo de transação.

Contabilidad y Negocios (16) 31, 2021 / e-ISSN 2221-724X 
Existem algumas premissas ou comportamentos esperados do mercado e dos indivíduos para que a teoria possa prever o comportamento das empresas quanto às transações (Williamson, 1979, Williamson \& Oichi, 1981; Williamson, 1985). A primeira dessas premissas está focada nos indivíduos e argumenta que os fornecedores tendem a agir de maneira oportunista, isso é, utilizam sua posição de poder, derivada da dependência das empresas para com eles, para mudar termos e valores de fornecimento.

De acordo com o autor, as altas variaçóes nos custos de transação das atividades ofertadas pelo mercado ocorrem porque os indivíduos se comportam de maneira oportunista. Sem esse comportamento o custo de transação do mercado seria mais baixo e estável pela baixa do custo com negociaçáo e desenvolvimento de contratos que buscam antever as interaçóes possíveis (Williamson, 1979). A segunda premissa é a racionalidade limitada, sendo esta a incapacidade cognitiva dos indivíduos de processar a infinita gama de informaçóes disponíveis do mesmo assunto, assim como o não acesso a todas as informaçôes relevantes. E também a incapacidade de relacionar e fazer cálculos probabilísticos sobre o futuro (Williamson, 1979).

A terceira premissa é a especificidade de ativos, alguns ativos podem ter características únicas ou exigir soluçôes complexas (exemplos: transporte, extração, condução, uso, maquinário e aparato técnico, descarte etc.) que os tornam capazes para obter e utilizar de forma mais específica para serem aproveitados. Isso acarreta no aumento da dependência da firma para com um número menor de fornecedores, já que esses itens não estão em elevada oferta para o mercado, encarecendo os produtos por uma equaçáo de oferta e demanda e encarece os custos com negociação, formulação de um contrato e monitoramento da transação, ou seja, os custos de transação (Williamson, 1985).
A quarta premissa é a incerteza, aqui reconhecida como informaçóes sobre passado, presente e futuro não perfeitamente conhecidas, que tornam mais difícil inferir sobre quem irá ou não agir de maneira oportunista, o que faz com que as empresas tomem uma posição mais defensiva e invistam tempo e dinheiro na negociação e formulação contratual, o que influencia diretamente o custo de transação (Williamson, 1979). Frequência de transaçóes é a quinta e última premissa sendo importante por dois fatores. Elevados números e volume de transações aumentam o nível de confiança entre as partes envolvidas e diminuem seus custos relativos, também igualam mais o poder de barganha entre o fornecedor e a empresa (Williamson, 1979).

Brouthers (2013) compilou o estudo de diversos autores que inferiam, com base nas premissas apresentadas, sobre a influência do custo de transação na seleção do modo de entrada. A análise sugeriu cinco pressupostos sobre tal influência e estão explanados a seguir.

Há estudo que reconhece que quando o custo de transação com negociação e monitoramento dos parceiros potenciais é baixo, empresas tendem a procurar parceiros para atuar em mercados estrangeiros, o que as levam a escolher modos de entrada que não envolvem investimentos diretos (Sinnewe, Charles \& Keast, 2016). Consequentemente, quando esses custos são altos, as empresas preferem realizar investimentos diretos, tendo em vista que, de acordo com Williamson (1979) as empresas tendem a ter melhor eficiência e estabilidade de custos (Erramilli \& Rao, 1993; Taylor, Zou \& Osland, 1998). Nesse entendimento, as características do ativo também são levadas em consideração no processo de escolha do método de entrada. As firmas que possuem mais especificidades de ativos geralmente têm maior custo de transação para resguardar e assegurar a integridade desse ativo visto que geralmente levam os parceiros a agir opor- 
tunisticamente. Para gerenciá-los, empresas que têm ativos mais específicos tendem a procurar métodos de entrada via investimentos, por serem menos dependentes de parceiros e fornecem controle. Em contraponto, firmas com ativos não tão específicos tendem a buscar a internacionalização via exportação ou métodos contratuais, pois necessitam de menor controle e oferecem menores riscos (Gatignon \& Anderson, 1988; Makino \& Neupert, 2000; Brouthers, 2013).

Outro fator de influência na escolha do modo de entrada é a estrutura burocrática necessária à entrada da empresa no país alvo, pois governos podem optar por excessivas legitimaçóes burocráticas para explorar e investir diretamente em seu território. Assim a empresa que deseja as transaçóes se depara com altos custos de aprendizagem dos processos legais assim como o próprio custo da legalização de suas atividades (North, 1990; Meyer, 2001). Sendo assim, empresas que entram em países que possuem diversas restriçóes legais para regular ingressantes de mercado tendem a escolher modos de entrada que desprendem menores investimentos, e que tenham maior suporte de parceiros externos, como o modo de exportação. Já empresas em mercados com poucas restriçóes a ingressantes externos tendem a selecionar modos de investimentos, pois não precisam de elevado auxílio para legalizar sua produção e isso reduz os custos de transação envolvidos no processo (Delios \& Beamish, 1999; Brouthers, 2013). Nesse sentido, há pesquisa que revela que as empresas procuram ingressar em mercados mais atrativos e que oferecem menores riscos (menor distância cultural e maior estabilidade social, econômica e política) (Leite \& Moraes, 2014). Estrategicamente, as firmas ingressam nesse tipo de mercado via investimento direto, considerando que mercados mais estáveis concedem maior retorno sobre o capital investido. Seguindo essa lógica, firmas ingressantes em mercados instáveis buscam modos de entrada que ligam a empresa a parceiros com alto conhecimento do mercado em questáo, na tentativa de amenizar as ameaças latentes. Firmas que se internacionalizam em mercados arriscados preferem modos menos diretos de internacionalização, como a exportação, para reduzir o comprometimento de recursos e assim mitigar a exposição ao risco (Delios \& Beamish, 1999; Brouthers, 2013).

Além disso, mercados com alto crescimento podem ter custo de oportunidade maior, ocasionado pelas diversas oportunidades de crescimento e oportunidades de precificação premium. Enquanto o custo de oportunidade em mercados com baixo crescimento tende a ser baixo, por ocorrência das poucas oportunidades de crescimento e das restriçóes nas estratégias de precificação (Agarwal \& Ramaswami, 1992; Kim \& Hwang, 1992; Brouthers \& Brouthers, 2000).

Já empresas que ingressam em mercados de alto crescimento (elevado potencial de mercado) tendem a preferir modos de entrada por investimento direto porque podem obter economias de escala, diminuindo o custo unitário de seus produtos e para estabelecer presença de longo tempo. Em mercados de baixo crescimento, ingressantes preferem modos de exportação e contratuais porque não causam tanto impacto no mercado o que evita brigas severas de preço com concorrentes, também porque esses modos podem ter melhor "custo/benefício", já que requerem menores desprendimentos de recursos e finalmente devido ao custo de saída do mercado náo ser alto, caso os retornos com as vendas de produtos e serviços não sejam satisfatórios (Kim \& Hwang, 1992; Agarwal \& Ramaswami, 1992; Brouthers, 2013). Portanto, a junção dessas duas teorias enriquece o campo de estudos teóricos sobre os modos de entrada. Finalizada a revisão teórica, segue-se com a apresentação dos caminhos metodológicos.

Contabilidad y Negocios (16) 31, 2021 / e-ISSN 2221-724X 


\section{Metodologia}

Creswel (2014) aponta que nas pesquisas qualitativas, configuradas pela predominância de dados descritivos, o ambiente foco é a fonte direta de dados e o pesquisador é o instrumento principal. Nesse tipo de investigação objetiva-se compreender como o objeto de estudo se manifesta nos processos e transaçóes cotidianas da empresa. Quanto ao procedimento técnico se trata de um estudo de caso qualitativo cuja unidade de análise é uma empresa do setor de sucata, com a comercialização de metais finos. Destaca-se que um dos pesquisadores é membro da organização. Além do critério de conveniência, a empresa W foi selecionada porque atendia a critérios definidos, quais sejam: possui transaçôes internacionais frequentes, atuação no mercado internacional há mais de 5 anos, solicitude no compartilhamento de informaçôes documentais e disponibilidade de gestores para participação de entrevistas. Também foi dada preferência à empresa por atuar em múltiplos mercados estrangeiros.

Seguindo as recomendaçóes para desenvolvimento de pesquisas qualitativas de Eisenhardt e Graebner (2007), este estudo contou com múltiplas fontes de coleta de dados, incluindo entrevista semiestruturada com o diretor e gerente de produção da empresa, observação participante e análise documental de arquivos fornecidos pela organização. Os sujeitos de pesquisa selecionados para a realização das entrevistas semiestruturadas foram: o diretor da empresa, pois efetivamente escolhe o modo de entrada utilizado e o gerente de produção, por acompanhar o processo de preparação e transporte dos produtos enviados ao exterior. Também foram utilizados dados secundários para complementar e fornecer entendimento da realidade em análise, esses dados são principalmente informaçóes sobre mudanças nos cenários político e econômico tanto do país sede da empresa quanto de outros países nos quais atua. Por último, os dados foram complementados por percepçóes decorrentes de observação participante, sendo um dos autores membro do núcleo estratégico da organização em estudo, resultando em um conjunto de notas de campo com informaçóes relevantes à pesquisa.

No total foram realizadas cinco entrevistas ao longo do processo de obtenção dos dados para a pesquisa, três com o diretor da W e duas com o gerente de produção da empresa. No primeiro momento foram realizadas entrevistas iniciais com ambos, a entrevista com o diretor durou aproximadamente uma hora e a entrevista com o gerente cerca de 40 minutos. Depois desse momento foram necessárias mais duas reunióes com cerca de 20 minutos com o diretor da empresa e uma reunião de aproximadamente 10 minutos com o gerente para sanar questionamentos que surgiram durante a estruturação dos resultados da pesquisa. Todas as entrevistas foram transcritas e, somadas aos documentos e notas de campo, constituíram o corpus da pesquisa.

A triangulação dos dados demandou constante reflexão dos pesquisadores (Yin, 2017), cujo ponto de saturação ocorreu ao passo em que as construçóes se tornaram mais robustas e estáveis. A codificação foi marcada por idas e vindas, um processo interativo em que as categorias de análise foram construídas e o desenho da pesquisa modelado (Gioia, Corley \& Hamilton, 2013; Zhang \& Wildemuth, 2016). A presença do rigor científico e da profundidade analítica estiveram presentes na fase de análise dos dados (Flick, 2009; Patton, 2002).

Os dados foram analisados a partir da utilização da técnica de análise de conteúdo, definida como um conjunto de técnicas de análise que envolve procedimentos sistemáticos e objetivos de descrição de 
conteúdo das informaçóes coletadas (Bardin, 2011). Trata-se de uma técnica apurada que exige muita dedicação, paciência e tempo do pesquisador, com uso da intuição, imaginação e criatividade na definição das categorias de análise (Mozzato \& Grzybovsky, 2011).

\section{Resultados}

A empresa selecionada, por motivo de privacidade é nomeada de W. Trata-se de uma firma que surgiu no ano de 2005 atuando como centro de coleta de matéria-prima de uma fundição multinacional brasileira que comercializa lingotes de alumínio. Em 2009 o conselho da multinacional decidiu trocar a direção da empresa W e contratou novo diretor para o qual ofereceram $20 \%$ da sociedade da empresa, esse diretor permanece administrando a empresa desde entáo. Em 2016, o diretor em questão comprou as cotas societárias dos demais sócios da empresa e atualmente é único proprietário.

A empresa W teve no início foco na comercialização de alumínio, mas atualmente atua na compra de mais de 20 categorias diferentes de metais não ferrosos, como cobre, zamack, off set, estanho, perfil, diversas ligas de inox, dentre outros. Segundo documentos internos, relativos ao início de 2020, a empresa contava com um quadro de aproximadamente 65 funcionários divididos em cinco departamentos: diretoria, compra, venda, financeiro, transporte, contábil fiscal e pessoal, produção e manutenção. A unidade de negócios é localizada na cidade de Maceió-AL. No início de 2020, era considerada a empresa do setor de sucata com maior volume de produção do nordeste brasileiro, movimentando anualmente aproximadamente 15 mil toneladas de metais, além de exportar parte de sua produção para países estrangeiros como a China, Índia, Estados Unidos, Espanha e Inglaterra.
O diretor da empresa relata que o que motivou a considerar o atendimento de mercados internacionais foi a oportunidade de reduzir os efeitos da sazonalidade dos produtos. Na visão dele, em 2011, após três anos dirigindo a empresa, observou certo padráo no comportamento do mercado nacional que reduzia drasticamente os números da empresa nos meses de dezembro e janeiro. Acontece que, empresas automobilísticas normalmente dão férias coletivas para seus operários nesses meses, para realizar manutençôes programadas nas máquinas o que diminui a demanda nacional de metais, já que essas empresas utilizam sucata metálica como matéria-prima na fabricação de diversas partes de seus modelos. Procurando alternativas de escoamento para os produtos, ele entáo começou a estudar novas possibilidades e acabou encontrando na internacionalização novo universo de atuação. Esperançoso com a oportunidade de dar novo destino aos estoques sazonais da empresa, saiu a procura de meios para realizar a comercializaçáo de seus produtos no exterior. Analisando o motivo que levou o gestor a buscar a internacionalização pode-se entender que nesse aspecto o caso estudado está em acordo com o que é proposto por Johanson e Vahlne (1977) quanto à identificação de oportunidades no mercado externo e o proposto por Root (1994) em relação à inatividade no mercado interno.

\subsection{Pressuposto da teoria}

A partir da análise dos dados pode-se observar a influência dos pressupostos na escolha do modo de entrada, baseados na TCT de Williamson (1979). Observou-se nas entrevistas bem como nas interaçóes decorrentes da observação participante, que a primeira preocupação do diretor concerne aos custos relacionados ao processo de internacionalização. Estudando os custos totais associados aos modos de entrada que ele considerava válidos para a empresa, buscou os bancos 
nacionais para analisar as possibilidades de obtenção de crédito para financiar a comercialização de produtos no exterior. Contudo, a empresa náo se encaixa nos quesitos de porte nem de garantias necessários para obter esse tipo de financiamento, o que levou o gestor a eliminar imediatamente a opção de investimento direto no exterior, por considerar como elevados os investimentos iniciais.

A não obtenção de crédito bancário forçou o diretor a voltar sua atenção para os modos de entrada via exportação, tendo em vista que requer comprometimento de recursos consideravelmente menor que os modos de investimento direto (Cavusgil et al., 2009; Hitt et al., 2018). Ponderando entre a exportação direta e a exportação indireta o gestor observou que apesar de ser mais lucrativa, a exportação direta apresentava maior custo de aprendizagem, retornos sobre investimento mais demorado e exigia conhecimento do mercado-alvo, o que o levou a escolher a exportaçáo indireta como opçáo inicial de exportação. $\mathrm{O}$ dirigente optou por realizar as exportaçóes (Iglesias \& Veiga, 2002; Peng, 2012) via colaboração com empresas brasileiras de trading. Essas empresas (trading companies) possuem conexóes com comerciantes de diversos segmentos em todo mundo, assim como atuam como intermediárias entre empresas locais que desejam exportar um produto e empresas externas que desejam obtê-lo. Essas empresas pagam o valor da carga ao exportador e negociam a revenda dela com clientes no exterior, realizando seu lucro, também se encarregam das questóes legais e logísticas do processo.

$\mathrm{Na}$ fala do gerente foi perceptível sua preocupação com o que chama de "custo de aprendizagem" no processo de internacionalização (Johanson \& Vahlne, 1977) e ao questionar por detalhes do custo, ele relata que são custos para a obtenção de informaçóes sobre a demanda do mercado estrangeiro, melhores rotas multimodais para transporte de cargas dentro e fora do país, parceiros de apoio no mercado-alvo e mesmo custos de legalização do processo etc. Notas de campo realizadas em reunióes estratégicas e comerciais da empresa reforçam essa preocupaçáo com os custos logísticos e relativos à confiança junto aos parceiros internacionais. Trazendo esses conceitos para o aspecto teórico, a junção desses custos pode ser resumida como o custo de busca, negociaçáo e manutenção do processo de exportação da empresa, o que é também considerado custo de transação por Williamson (1979).

O custo de transação tem forte influência no processo de internacionalização como sugere o primeiro pressuposto apresentado por Brouthers (2013), porém a relaçâo observada entre o custo de transação e a escolha no modo de entrada no caso estudado é inversa ao que se propóe a teoria. No caso apresentado apesar de evidente para o gestor que modos de entrada via investimento direto trariam significativa diminuição dos custos de transação se comparados aos modos via exportação, a empresa não possui recursos suficientes para optar por essa modalidade de modo de entrada. Isso leva à conclusão de que, apesar de fazer sentido no ambiente de recursos ilimitados, a teoria náo leva em consideração o porte das empresas que visam à exportação, e muitas delas, principalmente em países em desenvolvimento como o Brasil, não possuem o capital necessário para empreender nesse tipo de investimento (Taylor et al., 1998; Erramilli \& Rao, 1993).

A análise dos dados indicou que a condição essencial para seleção das tradings que fariam a exportação do material era a forma como seriam efetuados os pagamentos das cargas. Apenas seriam selecionadas as tradings que pagassem valor integral da carga antes de sair da empresa para transporte. $\mathrm{O}$ proprietário relata que durante os anos iniciais de exportação teve 
problemas com uma trading específica que inventou descontos indevidos na carga após sua chegada ao mercado-alvo e não pretende passar por essa experiência novamente.

Ainda sobre as tradings com as quais o empreendedor fez e ainda faz negócios, o gestor comentou que a presença de um agente parceiro com conhecimento da legislação do país alvo o auxiliou no processo de exportação pelo menos duas vezes. A primeira vez foi durante negociaçóes de cargas para os Estados Unidos, quando a trading o alertou do limite máximo de carga por container adentrando o território do país (20 toneladas) e comenta que o envio de containers mais pesados que isso gera sérios problemas com a fiscalização portuária e pode acarretar em punição à empresa exportadora e até mesmo no descadastramento e bloqueio permanente de envio de cargas.

A segunda ocorrência foi quando outra trading trabalhando com a organizaçáo orientou a empresa W a não enviar cápsulas de projéteis, itens frequentemente encontrados na sucata de latão, nos containers com destino à China, tendo em vista que essa possui política restrita contra a importação de quaisquer objetos relacionados a armas de fogo. Nesse caso, o descumprimento da regra poderia causar tribulaçóes para a empresa na ditadura ao mercado chinês e acarretar até mesmo problemas diplomáticos entre os países. Isso pode ser percebido tanto na fala do gestor quanto nos longos contratos de exportação expostos aos pesquisadores. Essa parte dos relatos auxilia na análise de duas premissas apresentadas na teoria de Williamson (1979), a incerteza e o risco percebido no mercado-alvo, que também são dois fatores importantes para a TCT e consequentemente para a escolha do modo de entrada. Nesse sentido, existe o pressuposto apresentado por Brouthers (2013) que utiliza essas premissas para basear suas conclusóes.
No terceiro pressuposto, o entrevistado argumenta que firmas ingressando em mercados que exigem muitos documentos e processos burocráticos de candidatos estrangeiros, geralmente demandam mais conhecimento dos candidatos. Por esse motivo empresas ingressantes, como ocorreu no caso relatado, geralmente procuram parceiros que detêm conhecimento do mercado desejado para minimizar os riscos (Meyer, 2001; North, 1990; Delios \& Beamish, 1999).

Observando os produtos da empresa evidencia-se que seus ativos são pouco específicos, o que já era esperado, visto que uma característica dos commodities é que esses produtos podem facilmente ser substituídos, tendo em vista que não existem variaçóes significativas entre as opçôes oferecidas pelo mercado e podem ser encontradas facilmente. Considerando que a empresa selecionou um modo de entrada via exportaçáo indireta, pode-se dizer que o que foi observado na empresa W está em acordo com o que é proposto pelo pressuposto teórico que afirma que empresas com ativos pouco específicos procuram modos de entrada via exportação, por não se preocupar tanto com a possibilidade de comportamentos oportunistas dos fornecedores (Williamson, 1985; Gatignon \& Anderson, 1988).

No relato do diretor da empresa evidencia-se que, apesar de não apresentar detalhes sobre a influência que a estabilidade sócio-política-econômica tem sobre a decisão de atendimento aos mercados, quando perguntado se faria exportaçóes para a Argentina, mesmo com as dificuldades citadas, ele afirma que consideraria fazer algumas exportações para o país:

Um belo dia eu recebi uma ligação de um cara, argentino [...]. Ele disse que tinha pesquisado no mercado e sabia da boa procedência minha e da empresa e que queria fazer negócio com a W [...]. No final acabamos não fazendo (negócio), a política econômica argentina está deixando muito difícil exportar para lá (Diretor da empresa W).

Contabilidad y Negocios (16) 31, 2021 / e-ISSN 2221-724X 
Essa afirmação está em pleno acordo com o que é proposto pelo quarto pressuposto. A situação política e econômica do país para a qual a empresa pretende exportar possui influência na decisão da viabilidade da transação. Essa relação pode ser observada no quarto pressuposto apresentado por Brouthers (2013), ao argumentar que empresas em arenas marcadas pela instabilidade social, política e econômica preferem reduzir a exposição ao risco e selecionar modos de entrada via exportação. Quando questionado se já havia considerado instalar uma subsidiária no mercado-alvo, o gerente de produção da empresa deu a seguinte resposta:

Eu acho que náo se classificaria como uma subsidiária, mas eu tenho vontade ainda de colocar uma pessoa, para negociar diretamente com os chineses [...]. O mercado chinês cresce muito, sempre. Isso é ótimo para quem mexe com sucata, porque quanto mais cresce mais precisa de sucata para fazer matéria-prima e mais sucata gerar.

Em vários momentos das entrevistas, tanto o diretor da empresa quanto o gerente de produçáo mencionaram que o mercado chinês era bem atrativo por sua crescente demanda de matéria-prima metálica e pelo crescimento do comércio em geral. Esse relato é valioso para observação do quinto pressuposto teórico apresentado por Brouthers (2013), pois nele, o gerente relata que tem desejo de atuar no mercado chinês por causa do crescimento e demanda, assim corrobora o previsto pelo pressuposto quando comenta que seu desejo é investir em algo semelhante a um representante comercial no mercado-alvo, o que já categoriza como modo de investimento no mercado externo. Isso está em pleno acordo com a suposição do pressuposto, que propóe que firmas ingressando em mercados que apresentam crescimento escolhem modos de entrada de investimento visando maximizar os lucros (Agarwal \& Ramaswami, 1992; Brouthers \& Brouthers, 2000).
Finalizada a discussão dos resultados, a próxima sessão apresentará as consideraçóes finais do estudo, envolvendo conclusões, limitaçôes da pesquisa e sugestôes para futuros estudos.

\section{Consideraçóes finais}

Este artigo teve como objetivo analisar, a partir da Teoria de Custo de Transaçáo, a escolha do modo de entrada em mercado internacional do maior trader comercial de metais finos do Nordeste, sediado na cidade de Maceió-AL. Os pressupostos baseados na TCT, desenvolvidos pelos diversos autores organizacionais citados e compilados por Brouthers (2013), têm relevância ao racionalizar o processo de decisão e gerar hipóteses que influenciam a decisão da empresa W sobre o modo de entrada.

Custo de transação, especificidade de ativos e burocracia relacionada à legalização foram os fatores propostos que apresentaram maior influência sobre a empresa W. Fatores como risco e crescimento de mercado também tiveram impacto na decisão tomada pela empresa devido ao porte e atual potencial de atuação, tais como relatados em relação às restriçóes de venda para Argentina e o crescimento do mercado chinês.

Pode-se compreender que apesar da teoria ter relativa aderência ao explicar algumas questóes organizacionais e mercadológicas relevantes, não é perfeita em suas abordagens e alcance, e não deve ser utilizada de forma exclusiva para justificar fenômenos organizacionais relativos à decisão por mercados estrangeiros. Outras teorias de internacionalização poderão explicar partes complementares e também relevantes.

Outro ponto importante é que essas correntes teóricas são oriundas da realidade de países desenvolvidos e de grandes empresas multinacionais. $O$ fato de fazer a opção pelo estudo de empresas de médio porte ins- 
taladas em países em desenvolvimento e cuja ação seja predominantemente o modelo comercial business to business pode exigir detalhes não abordados pelo conjunto teórico assumido, abrindo espaço para pesquisas futuras.

Estudos futuros podem ainda contemplar também outros aspectos do processo decisório e do empreendedorismo internacional em países em desenvolvimento, possivelmente mesclando aspectos de diferentes correntes teóricas de internacionalização via uma abordagem mais complexa. Por fim, este estudo representa um caso empírico em que é possível identificar pressupostos básicos que sustentam a teoria do custo de transação face às escolhas de mercados internacionais, sendo de interesse de atores públicos e privados que busquem compreender facetas da internacionalização a partir de países em desenvolvimento.

\section{Referências bibliográficas}

Agarwal, S., \& Ramaswami, S. N. (1992). Choice of Foreign Market Entry Mode: Impact of Ownership, Location and Internalization Factors. Journal of International Business Studies, 23(1), 1-28. https://doi. org/10.1057/palgrave.jibs.8490257

Andresen, M., \& Bergdolt, F. (2017). A Systematic Literature Review on the Definitions of Global Mindset and Cultural Intelligence: Merging Two Different Research Streams. The International Journal of Human Resource Management, 28(1), 170-195. https://doi.org /10.1080/09585192.2016.1243568

Bardin, L. (2011). Content analysis. São Paulo: Ediçóes.

Bennett, A., Bennett, D., Burstein, F., \& Holsapple, C. W. (2008). The Decision-Making Process for Complex Situations in a Complex Environment. Handbook on Decision Support Systems. New York: Springer-Verlag.

Brouthers, K. D. (2013). A Retrospective On: Institutional, Cultural and Transaction Cost Influences on Entry
Mode Choice and Performance. Journal of International Business Studies, 44(2), 14-22. https://doi. org/10.1057/jibs.2012.23

Brouthers, K. D., \& Brouthers, L. E. (2000). Acquisition or Greenfield Start-up? Institutional, Cultural and Transaction Cost Influences. Strategic Management Journal, 21(1), 89-97.

Brouthers, K. D., \& Brouthers, L. E. (2001). Explaining the National Cultural Distance Paradox. Journal of International Business Studies, 32(1), 177-189. https:// doi.org/10.1057/palgrave.jibs.8490944

Canabal, A., \& White III, G. O. (2008). Entry Mode Research: Past and Future. International Business Review, 17(3), 267-284. https://doi.org/10.1016/j. ibusrev.2008.01.003

Cassol, A., Novakowski, B. F. D., Dalbosco, I. B., \& Tonial, G. (2016, 20-22 de novembro). Estratégias de internacionalização: estudo multicasos de pequenas e médias empresas de Santa Catarina [Apresentação de simpósio]. V Simpósio Internacional de Gestáo de Projetos, São Paulo, Brasil.

Cavusgil, S. T., Knight, G., \& Riesenberge, R, J. R. (2009). Negócios internacionais: estratégia, gestão e novas realidades. São Paulo: Pearson.

Chiles, T. H., \& McMackin, J. F. (1996). Integrating Variable Risk Preferences, Trust, and Transaction Cost Economics. Academy of Management Review, 21(1), 73-99. https://doi.org/10.2307/258630

Coase, R. H. (1937). The Nature of the Firm. Econômica, 4(16),386-405.https://doi.org/10.1111/j.1468-0335. 1937.tb00002.x

Creswell, J. W. (2014). Qualitataive, Quantiative and Mixed Methods Approaches. Lincoln: Sage Publications.

Dhanaraj, C., \& Beamish, P. W. (2003). A Resource-Based Approach to the Study of Export Performance. Journal of Small Business Management, 41(3), 242-261. https://doi.org/10.1111/1540-627X.00080

Contabilidad y Negocios (16) 31, 2021 / e-ISSN 2221-724X 
Delios, A., \& Beamish, P. W. (1999). Ownership Strategy of Japanese Firms: Transactional, Institutional and Experience Influences. Strategic Management Journal, 20(10), 915-933. https://doi.org/10.1002/ (SICI) 1097-0266(199910)20:10<915::AID$\mathrm{SMJ} 51>3.0 . \mathrm{CO} ; 2-0$

Gatignon, H., \& Anderson, E. (1988). The Multinational Corpor- Ation's Degree of Control Over Foreign Subsidiaries: An Empirical Test of a Transaction Cost Explanation. Journal of Law, Economics and Organization, 4(2), 305-336.

Eisenhardt, K. M., \& Graebner, M. E. (2007). Theory Building from Cases: Opportunities and Challenges. The Academy of Management Journal, 50(1), 25-32. https://doi.org/10.5465/amj.2007.24160888

Erramilli, M. K., \& Rao, C. P. (1993). Service Firms' International Entry-Mode Choice: A Modified Transaction-Cost Analysis Approach. Journal of Marketing, 57(3), 19-38. https://doi. org/10.1177/002224299305700302

Flick, U. (2009). Desenho da pesquisa qualitativa. Porto Alegre: Artmed.

Gama, M. A. B., Lana, J., Calixto, C. V., \& Bandeira-deMello, R. (2016). Internacionalização de business group: a escolha do país de destino pela distância institucional. Revista Brasileira de Gestão de Negócios, 18(61), 327-347. https://doi.org/10.7819/rbgn.v18i61.2894

Gioia, D. A., Corley, K. G., \& Hamilton, A. L. (2013). Seeking Qualitative Rigor in Inductive Research: Notes on the Gioia Methodology. Organizational Research Methods, 16(1), 15-31. https://doi. org/10.1177/1094428112452151

Hitt, M. A., Ireland, R. D., \& Hoskisson, R. E. (2018). Administração estratégica: competitividade e globalização. São Paulo: Cengage.

Hymer, S. H. (1960). The International Operations of National Firms, A Study of Direct Foreign Investment (Doctoral dissertation, Department of Economy,
Massachusetts Institute of Technology. Cambridge, Massachusetts).

Iglesias, R. M., \& Veiga, P. (2002). Promoção de exportaçôes via internacionalização das firmas de capital brasileiro. Em A. C. Pinheiro, R. A. Markwald, \& L. V. Pereira (Orgs.), $O$ desafio das exportaçôes (pp. 368-446). Rio de Janeiro: Banco Nacional de Desenvolvimento Econômico e Social.

Johanson, J., \& Vahlne, J-E. (1997). The Internationalization Process of the Firm: A Model of Knowledge Development and Increasing Foreign Markets Commitments. Journal of International Business Studies, 8(1), 23-32. https://doi.org/10.1057/palgrave. jibs. 8490676

Johanson, J., \& Vahlne, J-E. (2009). The Uppsala Internationalization Process Model Revisited: From Liability of Foreignness to Liability of Outsidership. Journal of International Business Studies, 40(9), 1411-1431. https://doi.org/10.1057/jibs.2009.24

Kim, W. C., \& Hwang, P. (1992). Global Strategy and Multi- Nationals' Entry Mode Choice. Journal of International Business Studies, 23(1), 29-54. https:// doi.org/10.1057/palgrave.jibs. 8490258

Leite, Y. V. P., \& Moraes, W. F. A. (2014). Facetas do risco no empreendedorismo internacional. Revista de Administração Contemporânea, 18(1), 96-117. https://doi. org/10.1590/S1415-65552014000100007

Maia, J. M. (2003). Economia internacional e comércio exterior. São Paulo; Atlas.

Makino, S., \& Neupert, K. E. (2000). National Culture, Trans- Action Costs, and the Choice Between Joint Venture and Wholly Owned Subsidiary. Journal of International Business Studies, 31(4), 705-713. https:// doi.org/10.1057/palgrave.jibs. 8490930

Masten, S. E. (1993). Transaction Costs, Mistakes, and Performance: Assessing the Importance of Governance. Managerial and Decision Economics, 14(2) 119-129. https://doi.org/10.1002/mde.4090140205 
Meyer, K. E. (2001). Institutions, Transaction Costs, and Entry Mode Choice in Eastern Europe. Journal of International Business Studies, 32(2), 357-367. https:// doi.org/10.1057/palgrave.jibs.8490957

Meyer, K. E. (2015). Context in Management Research in Emerging Economies. Management and Organization Review, 11(3), 369-77. https://doi.org/10.1017/ mor.2015.36

Ministério da Industria, Comércio Exterior e Serviços. (2019). Exportação e Importação Geral. Recuperado de http://comexstat.mdic.gov.br/pt/geral [Consulta: 8 de novembro de 2019].

Mtigwe, B. (2006). Theoretical Milestones in International Business: The Journey to International Entrepreneurship Theory. Journal of International Entrepreneurship, 4(1), 5-25. https://doi.org/10.1007/s10843-006-5872-5

Mozzato, A. R., \& Grzybovski, D. (2011). Análise de conteúdo como técnica de análise de dados qualitativos no campo da administração: potencial e desafios. Revista de Administração Contemporânea, 15(4), 731-747. https:// doi.org/10.1590/S1415-65552011000400010

North, D. C. (1990). Institutions, Institutional Change and Economic Performance. Cambridge: Cambridge University Press. https://doi.org/10.1017/CBO97805118 08678

Oliver, C. (1997). Sustainable Competitive Advantage: Combining Institutional and Resource-Based Views. Strategic Management Journal, 18(9), 697-713. https:// doi.org/10.1002/(SICI) 1097-0266(199710)18:9< 697::AID-SMJ909>3.0.CO;2-C

Osland, G. E., Taylor, C. R., \& Zou, S. (2001). Selecting International Modes of Entry and Expansion. Marketing Intelligence \& Planning, 19(3), 153-161. https:// doi.org/10.1108/02634500110391690

Oviatt, B. M., \& McDougall, P. P. (1994). Toward a Theory of International New Ventures. Journal of International Business Studies, 25(1), 45-64. https://doi. org/10.1057/palgrave.jibs. 8490193
Patton, M. (2002). Qualitative Research and Evaluation Methods. Saint Paul: Sage Publications.

Peng, M. W. (2012). The Global Strategy of Emerging Multinationals from China. Global Strategy Journal, 2(2), 97-107. https://doi.org/10.1002/gsj.1030

Porter, M. E. (1999). Competição: estratégias competitivas essenciais. Rio de Janeiro: Campus.

Prange, C., \& Pinho, J. C. (2017). How Personal and Organizational Drivers Impact on SME International Performance: The Mediating Role of Organizational Innovation. International Business Review, 26(6), 11141123. https://doi.org/10.1016/j.ibusrev.2017.04.004

Roberts, P. W., \& Greenwood, R. (1997). Integrating Transaction Cost and Institutional Theories: Toward A Constrained-Efficiency Framework for Understanding Organizational Design Adoption. Academy of Management Review, 22(2), 346-373. https://doi. org/10.5465/amr.1997.9707154062

Root, F. R. (1994). Design Entry Strategy for International Markets. En F. R. Root (Ed.), Entry strategies for international markets (pp. 1-24). New York: Lexington Books.

Schellenberg, M., Harker, M. J., \& Jafari, A. (2018). International Market Entry Mode: A Systematic Literature Review. Journal of Strategic Marketing, 26(7), 601-627. https://doi.org/10.1080/0965254X.2017.1339114

Sharma, V. M., \& Erramilli, M. (2004). Resource-Based Explanation of Entry Mode Choice. Journal of Marketing Theory and Practice, 12(1), 1-8. https://doi.org/10 $.1080 / 10696679.2004 .11658509$

Shelanski, H. A., \& Klein, P. G. (1995). Empirical Research in Transaction Cost Economics: A Review and Assessment. Journal of Law, Economics, \& Organization, 11(2) 335-361.

Shrader, R. C. (2001). Collaboration and Performance in Foreign Markets: The Case of Young High-Technology Manufacturing Firms. Academy of Management Journal, 44(1), 45-60. https://doi.org/10.2307/3069336

Contabilidad y Negocios (16) 31, 2021 / e-ISSN 2221-724X 
Sinnewe, E., Charles, M. B., \& Keast, R. (2016). Australia's Cooperative Research Centre Program: A Transaction Cost Theory Perspective. Research Policy, 45(1), 195204. https://doi.org/10.1016/j.respol.2015.09.005

Steinbruch, F. K., Soares, M. C., Nunes, M. P., Perin, M. G., \& Sampaio, C. H. (2016). As variáveis relacionadas à escolha do modo de entrada em mercados internacionais. Revista de Administração de Roraima-UFRR, 6(1), 245270. https://doi.org/10.18227/2237-8057rarr.v6i1.3172

Taylor, C. R., Zou, S., \& Osland, G. E. (1998). A Transaction Cost Perspective on Foreign Market Entry Strategies of US and Japanese Firms. Thunderbird International Business Review, 40(4), 389-412. https:// doi.org/10.1002/tie.4270400405

Werner, S. (2002). Recent Developments in International Management Research: A Review of 20 Top Management Journals. Journal of Management, 28(3), 277-305.

Williamson, O. (1979). Transaction Cost Economics: The Governance of Contractual Obligations. Journal of Law and Economics, 22(2), 233-261. https://doi. org/10.1086/466942

Williamson, O. (1985). The Economic Institutions of Capitalism: Firms, Markets, Relational Contracting. Nova York: Free Press.

Williamson, O. (1994). Transaction Cost Economics and Organization Theory. En N. Smelser \& R. Swedberg
(Eds.), Handbook of Economic Sociology (pp. 70-107). Princeton: Princeton University Press.

Williamson, O., \& Ouchi, W. (1981). The Markets and Hierarchies Program of Research: Origins, Implications, Prospects. En A. Van De Ven \& W. F. Joyce (Eds.), Perspectives on Organizational Design and Behavior (pp. 347-406). New York: John Wiley \& Sons.

Yin, R. K. (2017). Case Study Research and Applications: Design and Methods. Saint Paul: Sage Publications.

Zahra, S. A., \& George, G. (2002). International Entrepreneurship: The Current Status of Held and Future Research Agenda. En M. A. Hitt et al. (Eds.), Strategic Entrepreneurship, Creating a New Mindset (pp. 255288). Oxford: Blackwell.

Zhang, Y., \& Wildemuth, B. M. (2016). Qualitative Analysis of Content. En B. M. Wildemuth (Ed.), Applications of Social Research Methods to Questions in Information and Library Science (pp. 318 -329). Santa Barbara: Libraries Unlimited.

Fecha de recepción: 10 de setiembre de 2020 Fecha de aceptación: 06 de noviembre de 2020

Correspondencia: mathalvesteofilo@gmail.com viniciusfmoreira@yahoo.com.br yakarav@gmail.com 